\title{
QUALITATIVE AND QUANTITATIVE OF PHYTOCHEMICAL ANALYSIS OF MALAYSIAN Euphorbia milii (EUPHORBIACEAE) AND ITS ANTIOXIDANT ACTIVITIES
}

\author{
NUR SYAFIKA AMANI ABD. MUTALIB ${ }^{1}$, NORHAYATI YUSUF ${ }^{1,3}$, ASNUZILAWATI ASARI $^{1,2}$, \\ AHMAD NAZIF AZIZ1,2 and NURUL HUDA ABDUL WAHAB ${ }^{1,2 *}$ \\ ${ }^{I}$ Faculty of Science and Marine Environment, Universiti Malaysia Terengganu, \\ 21030, Kuala Nerus, Malaysia \\ ${ }^{2}$ Advanced Nano Materials (ANoMa) Research Group, Universiti Malaysia Terengganu, 21030, \\ Kuala Nerus, Malaysia \\ ${ }^{3}$ Biological Security and Sustainability (Bioses) Research Interest Group, \\ Universiti Malaysia Terengganu, 21030, Kuala Nerus, Malaysia \\ *E-mail:nhuda@umt.edu.my
}

Accepted 9 December 2020, Published online 25 December 2020

\begin{abstract}
Euphorbiaceae plants had been traditionally used in healing various diseases. This study was designed to determine the secondary metabolites that exist in Malaysian Euphorbia milii (Euphorbiaceae) and it's potential in antioxidant activities. Dried leaves and flowers of $E$. milii were extracted using hexane, ethyl acetate, and methanol. The qualitative and quantitative phytochemical analysis was performed toward the crude extracts. The outcomes showed that alkaloids, flavonoids, quinones, carbohydrates, and reducing sugar were mainly present in all of the samples extracted by the three solvents. For quantitative analysis, methanolic leaves extract contained the highest amount of flavonoids, given as $0.0867 \pm 0.005 \mathrm{mg} \mathrm{QE} / \mathrm{g}$ of the sample compared to other extracts. Meanwhile, the determination of antioxidant activities of each extract showed that methanol leaves extract consists of the highest antioxidant activity due to the presence of phytochemical compounds. This significant data provides preliminary findings that may lead to further development as a potential source of herbal medicine.
\end{abstract}

Key words: Euphorbia milii, Euphorbiaceae, phytochemical screening, total flavonoid content, antioxidant activities

\section{INTRODUCTION}

Antioxidant plays crucial role in combating oxidative stress (OS) that had become the reasons for varieties of chronic diseases such as cancer, cardiovascular disease, and Alzheimer's disease. However, this natural antioxidant mechanism can be inefficient due to bad dietary habits. This had been an important reason for the production of medicinal or dietary supplements that use synthetic antioxidants as their main ingredient. Unfortunately, in the recent past, some toxicological studies regarding the use of synthetic antioxidants have shown their unwanted or adverse effects (Anwar et al., 2018). Hence, researchers need to go back to nature and identify or provide optional natural sources of antioxidants.

\footnotetext{
* To whom correspondence should be addressed.
}

Euphorbia milii have been known as a rich source of bioactive constituents. E. milii is a decorative, cosmopolitan plant that belongs to the family of Euphorbiaceae. This plant is commonly known as the "Crown of Thorn" among Malaysians. The leaves of this plant used for medicinal uses including antiseptic, antibacterial, anticancer, antiinflammatory effects, and mild hypersensitive properties (Okwu, 2004; Pradyutha et al., 2015). According to the study carried out by Kamurthy et al. (2015), the obtained compounds of E. milii flowers are effective pharmaceutical compounds that will serve as a better alternative to chemicalbased pharmaceuticals. Therefore, this study was carried out to provide data on the presence of the secondary metabolites in different parts of E. milii extracts and the consequence toward the antioxidant properties. 


\section{MATERIALS AND METHODS}

\section{Plant materials}

Two different parts (flowers and leaves) of the Euphorbia milii plant were collected from Kota Tinggi, Johor. The botanical identity of the plant specimen of E. milii was confirmed by Tuan Haji Razali Salam of the Biological Laboratory, Universiti Malaysia Terengganu.

\section{Sample extraction}

The materials were cleaned under running tap water and dried at room temperature for seven days before ground into powder form using a grinder. Then, the plant powders were extracted by soaking them with three different solvents with different polarities (Sigma-Aldrich, US) at room temperature for three days. Then, each extract was concentrated using a rotary evaporator (Büchi Rotavap R-200 $\mathrm{CH}-9230$, Switzerland) under reduced pressure at $35-40^{\circ} \mathrm{C}$ for $15 \mathrm{~min}$. The crude extracts obtained were weighed and stored in a chiller $\left(4^{\circ} \mathrm{C}\right)$ for further analysis.

\section{Qualitative phytochemical analysis}

All crude extracts were subjected to eleven phytochemical tests which were alkaloids test, saponins test, tannin test (Braymer's test) (Morsi, 2014), triterpenoid and steroid test (Yelin \& Kuntadi, 2019), flavonoids test $\left(\mathrm{H}_{2} \mathrm{SO}_{4}\right.$ test), phlobatannins test (Coolborn et al., 2015), quinones test (Amabye et al., 2016), reducing sugar test (Fehling's test) (Karki, 2018), carbohydrate test (iodine test) (Karki, 2018), phenolic content test (ferric chloride test) (Pant et al., 2017).

\section{Quantitative phytochemical analysis}

\section{Determination of total flavonoid contents}

The total flavonoid content was determined by using the aluminum chloride colorimetric method (Afify et al., 2012; Khan et al., 2018) using a UV- spectrophotometer (Shimadzu, UV-Vis 1800). Quercetin (Sigma - Aldrich, US) was used to make the calibration curve. The total flavonoid content was expressed in terms of quercetin equivalent (mg QE/g of the sample).

\section{Antioxidant activity (AOA)}

\section{Total antioxidant activity}

Antioxidant activity was measured by the paired diene method (Lingnert et al., 1979; Alfatemi et al., 2015) using a spectrophotometer (Shimadzu, UVVis 1800). $\alpha$-tocopherol (Sigma - Aldrich, US) was used as standard controls. The total antioxidant activity was calculated as follows:

$$
=\left[\frac{\left(\Delta A_{234} \text { of control }-\Delta A_{234} \text { of sample }\right)}{\Delta A_{234} \text { of control }}\right] \times 100
$$

\section{Free radical scavenging assays}

\section{Scavenging effect on DPPH radical}

The free radical scavenging activity of E. milii was determined by the 1,1-diphenyl-2-picryl hydroxyl (DPPH) method (Shekhar et al., 2014). Here, only those extracts that soluble in ethanol were used, and various concentrations were prepared by dilution method. The reduction of DPPH free radical was measured by reading the absorbance at $517 \mathrm{~nm}$ by using a UV- spectrophotometer (Shimadzu, UV-Vis 1800). The $\mathrm{IC}_{50}$ value of extract, which is the concentration of the sample required to inhibit $50 \%$ of the DPPH free radical was calculated by the graphical method by plotting percent inhibition versus concentration. The DPPH radical scavenging effect (\%) was calculated using the following formula:

$$
\text { Scavenging effect }(\%)=\left[\frac{\left(A_{o}-A_{1}\right)}{A}\right] \times 100 \%
$$

Where $\mathrm{A}_{\mathrm{o}}$ was the absorbance of the control, and $A_{1}$ was the absorbance of the test sample.

\section{Non-enzymatic antioxidant assays}

\section{Determination of $\alpha$-tocopherol}

$\alpha$-Tocopherol was determined according to the method proposed by Kanno and Yamauchi (1997) (Norhayati et al., 2011). The absorbance was measured at $554 \mathrm{~nm}$ by using a UVspectrophotometer (Shimadzu, UV-Vis 1800). A standard curve was prepared using $\alpha$-tocopherol (Sigma - Aldrich, US) at various concentrations $(0-1.4 \mu \mathrm{g} / \mathrm{mL})$. Then, the $\alpha$-tocopherol in the extracts was calculated based on the standard curve.

\section{Determination of carotenoids}

Carotenoid content was extracted referring to the method proposed by Lichtenthaler (1987) (Norhayati et al., 2011). Under dim light and over ice, $0.02 \mathrm{~g}$ of fresh samples were ground up with $3.0 \mathrm{~mL}$ of $80 \%(\mathrm{v} / \mathrm{v})$ acetone (Sigma - Aldrich, US) in mortar and pestle. The homogenates were centrifuged at $10000 \mathrm{rpm}$ for $10 \mathrm{~min}$. The absorbance of the supernatant obtains was measured at 663.2, 646.8, and $470 \mathrm{~nm}$. As the blank, 80\% acetone was used as blank. Carotenoids content was calculated using the formula: 


$$
\begin{aligned}
& \mathrm{C}_{\mathrm{a}}=12.25 A_{663.2}-2.79 A_{646.8} \\
& \mathrm{C}_{\mathrm{b}}=21.50 A_{646.8}-5.1 A_{663.2} \\
& \mathrm{C}_{x+c}=\frac{1000 A_{470}-1.82 C_{a} 85.02 C_{b}}{198}
\end{aligned}
$$

Where $\mathrm{C}_{\mathrm{a}}$ : chlorophyll a $(\mathrm{mg} / \mathrm{mL}), \mathrm{C}_{\mathrm{b}}$ : chlorophyll $\mathrm{b}(\mathrm{mg} / \mathrm{mL}), \mathrm{C}_{\mathrm{x}+\mathrm{c}}$ : carotenoids $(\mathrm{mg} / \mathrm{mL})$.

\section{Statistical analysis}

Data are reported as mean \pm standard error of six independent experiments. The data were analyzed using one-way ANOVA and Tukey's posttest. A difference was considered statistically significant at $p<0.05$.

\section{RESULTS AND DISCUSSION}

\section{Qualitative phytochemical analysis}

In the present study, several phytochemical constituents were revealed in the E. milii plant. Alkaloids, flavonoids, quinones, carbohydrates, and reducing sugar were mainly present in all crude extracts. Previous research on leaves extracts (hexane, ethyl acetate, and methanol) of E. milii by Pradyutha et al. (2015) revealed the presence of alkaloids, flavonoids, carbohydrates, and reducing sugar in all of the crude extracts. Kamurthy et al. (2015) reported the findings of flavonoids, phenolic compounds, and triterpenoids extract in the flower extracts of E. milii and managed to isolate two triterpenoids, one flavone and two phenolic compounds from the red flowers of E. milii. In the part of that, saponin has an important role as a part of the plant's defense system. Yet, only ethyl acetate leaves extract produce stable bubble froth which indicated the presence of saponins. This findings aligned with the data obtained by Pradyutha et al. (2015). Some research suggested that the distribution and composition of saponins in plants might be a reflection of varying needs for plant protection (Kregiel et al., 2017). For the phenolic content test and tannin test, only ethyl acetate and methanol extracts of flowers and leaves gave a positive result. These obtained results were supported by the study done by Maneesha and Sudha (2018). The hexane crude extracts and ethyl acetate crude extracts of flowers showed changes of color to a redness which indicated the presence of triterpenoid meanwhile the other crude extracts showed green or greenish-blue coloration indicated the presence of steroids. The presence of steroids in ethyl acetate leaves and all methanol extracts indicated the presence of highly polarities of steroids. Meanwhile, the triterpenoids exist as low polarities compounds. In referring to the study done by Rauf et al. (2014) and Salehi et al. (2019), steroids and triterpenoids can be found in most of the Euphorbiaceae species including E. milii. However, no detection for phlobatannins test and in agreement with the data obtained from Rauf et al. (2014). The overall results of qualitative phytochemical analysis tests is presented in Table 1.

\section{Quantitative phytochemical analysis}

\section{Determination of total flavonoids content}

Among all the crude extracts, methanol leaves extract has the highest flavonoid content $(0.0837 \pm$ $0.005 \mathrm{mg} \mathrm{QE} / \mathrm{g}$ of the sample) followed by ethyl acetate leaves $(0.0585 \pm 0.001 \mathrm{mg} \mathrm{QE} / \mathrm{g}$ of the sample), methanol flowers extract $(0.0484 \pm 0.003$ $\mathrm{mg} \mathrm{QE} / \mathrm{g}$ of the sample) and hexane leaves extract $(0.0412 \pm 0.002 \mathrm{mg} \mathrm{QE} / \mathrm{g}$ of the sample $)$. Nonetheless, the lowest flavonoid content was discovered

\begin{tabular}{|c|c|c|c|c|c|c|}
\hline \multirow{2}{*}{ Phytochemical test } & \multicolumn{2}{|c|}{ Hexane } & \multicolumn{2}{|c|}{ Ethyl acetate } & \multicolumn{2}{|c|}{ Methanol } \\
\hline & Flower & Leaves & Flower & Leaves & Flower & Leaves \\
\hline Alkaloid Test & + & + & + & + & + & + \\
\hline Triterpenoid Test & + & + & + & - & - & - \\
\hline Steroid Test & - & - & - & + & + & + \\
\hline aFlavonoid Test & + & + & + & + & + & + \\
\hline Quinones Test & + & + & + & + & + & + \\
\hline Phlobatannins Test & - & - & - & - & - & - \\
\hline Saponins Test & - & - & - & + & - & - \\
\hline Reducing Sugar Test & + & + & + & + & + & + \\
\hline Carbohydrate Test & + & + & + & + & + & + \\
\hline Phenolic Content Test & - & - & + & + & + & + \\
\hline Tannin test & - & - & + & + & + & + \\
\hline
\end{tabular}
from the flower extracts; ethyl acetate $(0.0402 \pm$

Table 1. Summary of qualitative phytochemical analysis tests on crude extracts of $E$. milii

${ }^{*}-$ : Negative result. $\quad+$ : Positive result. 
$0.004 \mathrm{mg} \mathrm{QE} / \mathrm{g}$ of the sample) and hexane (0.0296 $\pm 0.006 \mathrm{mg} \mathrm{QE} / \mathrm{g}$ of the sample). Referring to the parts of the plant, the highest flavonoid content was contributed by leaves part with $0.1835 \mathrm{mg} \mathrm{QE} / \mathrm{g}$ of sample and followed by flowers, which was 0.1182 $\mathrm{mg} \mathrm{QE} / \mathrm{g}$ of the sample. Figure 1 summarizes the estimation of flavonoid contents in different crude extracts of E. milii.

Based on the result, we observed that the methanol solvent could provide higher flavonoids compounds. Different polarities of the extractions solvent will provide different types of compounds because of their variable chemical nature and sensitivity toward extraction or hydrolysis (Isfahlan et al., 2010). This is also supported by the study E. hirta done by Ismail et al., (2019). Most flavonoid compounds were found in leaves extract due to the photosynthesis in leaves (Saboonchian et al., 2014) in which parallel with the findings of this study.

\section{Antioxidant activity (AOA)}

\section{Total antioxidant activity}

From this test, methanolic leaves extract shown the highest percentage of total antioxidant activity with $73 \pm 0.5 \%$ followed by methanol flowers extract $(71 \pm 2.0 \%)$, ethyl acetate leaves extract
$(45 \pm 4.4 \%)$ and lastly ethyl acetate flowers extract (35 $\pm 0.8 \%$ ). For the standard $\alpha$-tocopherol, the percentage of antioxidant activity was $86 \pm 0.0 \%$. The highest inhibition of linoleic acid-lipid radical in methanolic leaves extract may be due to the high presence of flavonoids compounds that consist of the hydroxyl group and carbonyl group as obtained in the quantitative phytochemical analysis. This finding was in agreement by Loganayaki et al. (2013) where the inhibition of lipid peroxidation might be due to the hydrogen ability of phenolic derivatives and subsequent radical stabilization. Figure 2 shows the percentage of total antioxidant activity toward E. milii extracts.

\section{Free radical scavenging assays}

\section{Scavenging effect on DPPH radical}

The results obtained revealed that all of the plant samples shown positive results toward this test. The methanolic leaves sample seen to have a higher percentage of scavenging effect (70.76 \pm $0.4 \%)$ followed by flowers $(67.77 \pm 0.0 \%)$ meanwhile the standard ascorbic acid was $(99.94 \pm 0.0 \%)$ at the concentration of $25 \mu \mathrm{g} / \mathrm{mL}$. Besides, after performing $\mathrm{IC}_{50}$, the value obtained was as 0.0346 , 1.4483 , and $2.2781 \mu \mathrm{g} / \mathrm{mL}$ for ascorbic acid,

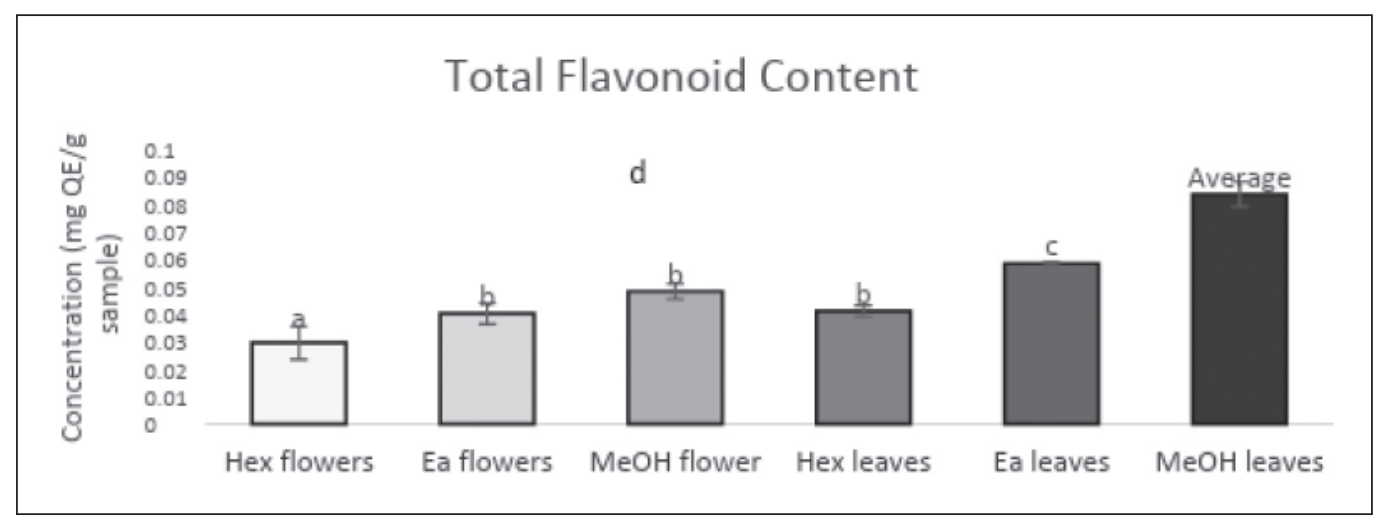

Fig. 1. Determination of total flavonoids content in different crude extracts of E. milii ( $n=6)$.

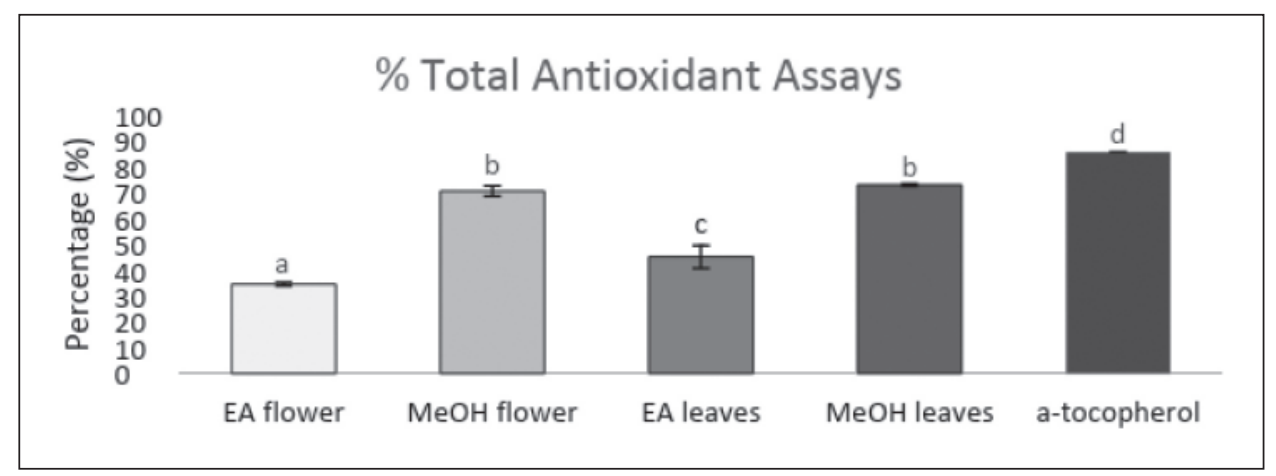

Fig. 2. Percentage of total antioxidant activity toward E. milii extracts $(n=5)$. 
methanol leaves extract, and methanol flowers extract, respectively. It means the methanolic extracts of E. milii at a higher concentration able to inhibit more free radicals formed by DPPH radical resulting in a decreasing of absorbance against the concentration and an increase in $\mathrm{IC}_{50}$ value. The effects of antioxidants on DPPH radical scavenging were due to their hydrogen-donating ability of the polyphenolic compounds in the extracts to act as inhibitors or scavengers (Khan et al., 2013). Figure 3 shows the percentage of scavenging effect on DPPH Radical.

\section{Non-enzymatic antioxidant assays}

\section{Determination of $\alpha$-tocopherol}

The leaves part shows the higher amount of $\alpha$-tocopherol $(0.4907 \pm 0.01 \mu \mathrm{g} / \mathrm{mL})$ followed by flowers $(0.3101 \pm 0.01 \mu \mathrm{g} / \mathrm{mL})$. This data related closely with the findings of research done by Inoue et al. (2017) toward 81 plants including E. stenocardia Baill and Jatropha curcus L. (Euphorbiaceae). In addition, the most abundant type of tocopherol present in leaves is $\alpha$-tocopherol (Shintani et al., 1998; Grusak et al., 1999; Fritsche et al., 2017) except for crops including wild Euphorbia species that produce seeds (Bruni et al., 2004; Fritsche et al., 2017).

\section{Determination of carotenoids}

Based on the results obtained, leaves part showed the highest carotenoid content $(0.7605 \pm$ $0.2 \mu \mathrm{g} / \mathrm{mL})$ as compared to flowers $(0.3814 \pm 0.04$ $\mu \mathrm{g} / \mathrm{mL}$ ). According to Puzon et al. (2015), carotenoids were highly contained in young and matured leaves of E. hirta L. compared to the flowers in which aligned with the result obtained. Table 2 showed the summary of non-enzymatic antioxidant assays toward E. milii.

In this study, different polarities of solvents have been used to extracts different classes of compounds from the E. milii plant. The outcome showed that the methanolic leaves extract of E. milii was revealed to have the highest antioxidants activity due to the highest flavonoid content compared to other crude extracts. This is also proven by the ethanolic extracts of E. hirta that possess the highest antioxidant activities that also recorded to have the highest flavonoid content (Venkatachalam et al., 2018). However, there is an obvious difference between the results of the extracts and the standard control used ( $\alpha$-tocopherol and ascorbic acid). This might be due to the low concentration of bioactive compounds that exist in the extracts compared to the pure standard control. Although phenolic compounds are responsible for their antioxidant behavior, however other factors may also caused the increasing and decreasing of the antioxidant activity such as the presence of electronwithdrawing or releasing group in the aromatic ring (Rosalind et al., 2013; Devi et al., 2016). In referring to the part of plants, the leaves of E. milii showed to possess the better activities compared to flowers due to the presence of phytochemical compounds parallel with research carried out by Abu Arra Basma et al. (2011) toward E. hirta L.

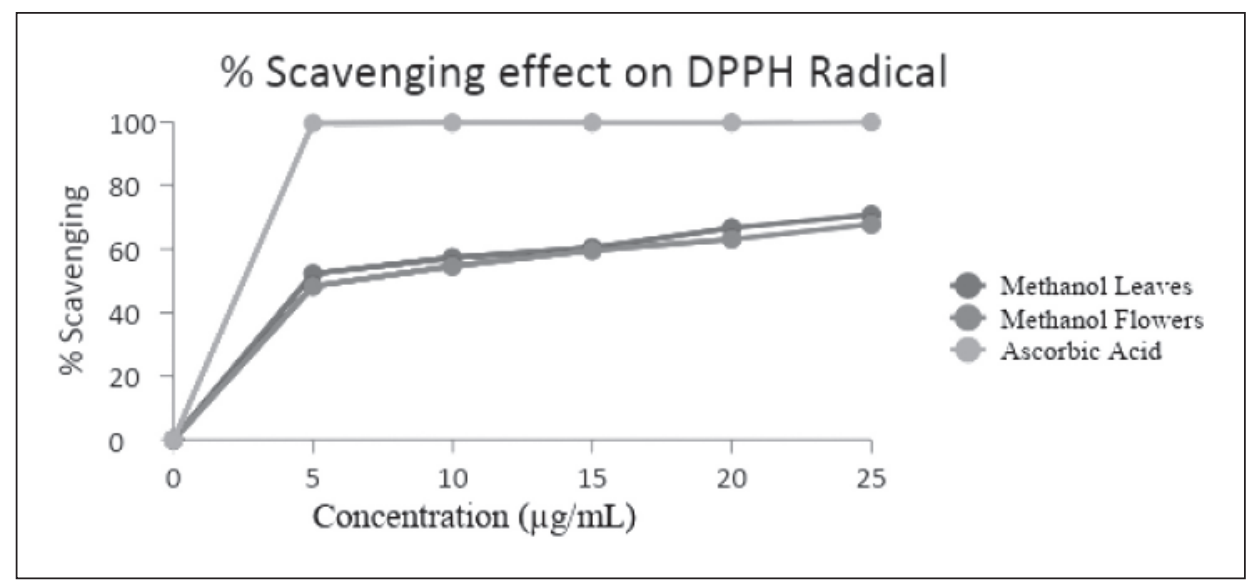

Fig. 3. Percentage of scavenging effect on DPPH Radical $(n=3)$.

Table 2. Summary of non-enzymatic antioxidant assays toward E. milii

\begin{tabular}{ccc}
\hline Non- enzymatic antioxidant assays & Leaves & Flowers \\
\hline$\alpha$-tocopherol & $0.4907 \pm 0.01 \mu \mathrm{g} / \mathrm{mL}$ & $0.3101 \pm 0.01 \mu \mathrm{g} / \mathrm{mL}$ \\
Carotenoids & $0.7605 \pm 0.2 \mu \mathrm{g} / \mathrm{mL}$ & $0.3814 \pm 0.04 \mu \mathrm{g} / \mathrm{mL}$ \\
\hline
\end{tabular}


Similar observations were obtained by the study done by Gapuz and Besagas (2018) where E. milii showed to have the highest antioxidants activity compared to E. trigona and E. antiquorum due to the highest amount of flavonoids and phenolic compounds exist in the methanolic leaves extract. The production, composition, and distribution of phytochemical compounds were caused by the chemical interaction between plant and environmental factors such as humidity, nutrition in the soil, and temperature changes (Sampaio et al., 2016). Therefore, we observed the difference in classes, structure, and amount of phytochemical compounds that have been identified and recorded in other previous research that used the same species, E. milii as their samples. Thus, our findings provide significant data on the strong correlation between flavonoids content and the antioxidant activity presence in E. milii that might be useful in discovering new potential drugs.

\section{CONCLUSION}

This study discovered that E. milii has a wide variety of bioactive metabolite make this plant to possess antioxidant properties. However, further investigation needs to be done focusing on isolation and identification of bioactive compounds that present in E. milii to discovered other potential applications on healing diseases.

\section{ACKNOWLEDGEMENTS}

The authors would like to express appreciation to the Faculty of Science and Marine Environment, Universiti Malaysia Terengganu for providing laboratory facilities and UMT-TAPE-RG (Vote: 55159) for financial support.

\section{REFERENCES}

Abu Arra Basma, Zuraini, Z., Latha, L.Y., Sasidharan, S. 2011. Antioxidant activity and phytochemical screening of the methanol extracts of Euphorbia hirta L. Asian Pacific Journal of Tropical Medicine, 4: 386-390.

Alfatemi, S.M., Rad, J.S., Rad, M.S., Mohsenzadeh, S. \& da Silva, J.A. 2015. Chemical composition, antioxidant activity and in vitro antibacterial activity of Achillea wilhelmsii C. Koch essential oil on methicillin-susceptible and methicillinresistant Staphylococcus aureus spp. Biotech, 5(1): 39-44.
Amabye, T.G., Bezabh, A.M. \& Mekonen, F. 2016. Phytochemical constituents and antioxidant activity of Delonix elata L. in flower extract. Journal of Analytical \& Pharmaceutical Research, 2(1): 00006.

Anwar, H., Hussain, G. \& Mustafa, I. 2018. Antioxidants from natural sources. In: Antioxidants in Foods and Its Applications. E. Shalaby and G.M. Azzam (Eds.). IntechOpen.

Azzahra, L.F., Fouzia, H., Mohammed, L. \& Noureddine, B. 2012. Antioxidant response of Camellia sinensis and Rosmarinus officinalis aqueous extracts toward $\mathrm{H}_{2} \mathrm{O}_{2}$ stressed mice. Journal of Applied Pharmaceutical Science, 2(07): 70-76.

Coolborn, A.F., Bolatito, B., Omolara, A.V. \& Adetuyi, F.C. 2015. Phytochemical and antioxidant effect of Spathodea campanulata leaf extracts. International Journal of Biochemistry Research \& Review, 7: 148-159.

Devi, U., Devi, T.I. \& Singh, T.C. 2016. Phytochemical screening on three traditional medicinal plants against piles. International Journal of Research - GRANTHAALAYAH, 4(5): 99-105.

Fritsche, S., Wang, X. \& Jung, C. 2017. Recent advances in our understanding of tocopherol biosynthesis in plants: An overview of key genes, functions, and breeding of vitamin e improved crops. Antioxidants, 6(4): 99.

Gapuz, M.C. \& Besagas, R.L. 2018. Phytochemical profiles and antioxidant activities of leaf extracts of euphorbia species. Journal of Biodiversity and Environmental Sciences, 12(4): 59-65.

Inoue, T., Honma, S., Otsuka, Y., Nakane, T. \& Takano, A. 2017. Distribution of eight vitamin e homologs found in 81 plants using LC-MS3. Journal of Nutrition and Food Science, 7: 636.

Isfahlan, A.J., Mahmoodzadeh, A., Hassanzadeh, A., Heidari, R. \& Jamei, R. 2010. Antioxidant and antiradical activities of phenolic extracts from Iranian almond (Prunus amygdalus L.) hulls and shells. Turkish Journal of Biology, 34: 165-173.

Ismail, A., Mohamed, M., Kwei, Y.F. \& Yin, K.B. 2019. Euphorbia hirta methanolic extract displays potential antioxidant activity for the development of local natural products. Pharmacognosy Research, 11: 78-85.

Kamurthy, H., Dontha, S. \& Rajani, K. 2015. Phytochemical screening on Euphorbia milii red flowers - Isolation of terpenoids, flavone and phenols. American Journal of Ethnomedicine, 2(6): 322-332. 
Karki, G. 2018. Fehling's Test: Objective, principle, reagents, procedure and result [WWW Document]. URL https://www.onlinebiology notes.com/fehlings-test-objective-principlereagents-procedure-and-result/ (accessed 6.21.2019).

Karki, G. 2018. Tests for specific carbohydrates: Seliwanoff's test, Bial's test and Iodine test [WWW Document]. URL https://www.online biologynotes.com/tests-for-specificcarbohydrates-seliwanoffs-test-bials-test-andiodine-test/ (accessed 6.21.2019).

Khan, M.A., Rahman, A.A. \& Islam, S. 2013. A comparative study on the antioxidant activity of methanolic extracts from different parts of Morus alba L. (Moraceae). BMC Research Notes, 6: 24.

Khan, M.S., Yusufzai, S.K., Rafatullah, M., Sarjadi, M.S. \& Razlan, M. 2018. Determination of total phenolic content, total flavonoid content and antioxidant activity of various organic crude extracts of Licuala spinosa leaves from Sabah, Malaysia. ASM Science Journal, 11(3): 53-58.

Kregiel, D., Berlowska, J., Witonska, I., Antolak, H., Proestos, C., Babic, M., Babic, L. \& Zhang, B. 2017. Saponin-based, biological-active surfactants from plants. In: Application and Characterization of Surfactants. R. Najjar (Ed.). IntechOpen.

Loganayaki, N., Siddhuraju, P. \& Manian, S. 2013. Antioxidant activity and free radical scavenging capacity of phenolic extracts from Helicteres isora L. and Ceiba pentandra L. Journal of Food Science and Technology, 50(4): 687-695.

Maneesha, S. \& Sudha. 2018. Evaluation of phytochemical and antibacterial activity of Euphorbiaceae members against human pathogens. International Journal of Recent Scientific Research, 9(8(D)): 28534-28538.

Morsi, N. 2014. Phytochemical analysis of biologically active constituents of medicinal plants. Main Group Chemistry, 13: 7-21.

Norhayati, Y., Nor'Aini, M.F., Misri, K., Marziah, M. \& Azman J. 2011. $\alpha$-Tocopherol, ascorbic acid and carotenoid content in Centella asiatica leaf tissues and callus cultures. Pertanika Journal of Tropical Agricultural Science, 34(2): 331-339.

Pant, D.R., Pant, N.D., Saru, D.B., Yadav, U.N. \& Khanal, D.P. 2017. Phytochemical screening and study of antioxidant, antimicrobial, antidiabetic, anti-inflammatory and analgesic activities of extracts from stem wood of Pterocarpus marsupium Roxburgh. Journal of Intercultural Ethnopharmacology, 6(2): 170176.
Pradyutha, A.C. \& Rao, U.M. 2015. Phytochemical screening and antimicrobial evaluation of Euphorbia milii leaf extracts. World Journal of Pharmaceutical Research, 8(1): 1626-1633.

Puzon, J.J.M., Tabayoyong, E.R. \& Jumawan, H.J.M. 2015. Morpho-physiological changes in Euphorbia hirta L. in response to mercury exposure. Philippine Journal of Science, 144(2): 161-170.

Rauf, A., Khan, A., Uddin, N., Akram, M., Arfan, M., Uddin, G. \& Qaisar, M. 2014. Preliminary phytochemical screening, antimicrobial and antioxidant activities of Euphorbia milli. Pakistan Journal of Pharmaceutical Science, 27: 947-951.

Saboonchian, F., Jamei, R. \& Sarghein, S.H. 2014. Phenolic and flavonoid content of Elaeagnus angustifolia L. (leaf and flower). Avicenna Journal of Phytomedicine, 4(4): 231-238.

Sampaio, B., Edrada-Ebel, R. \& Da Costa, F. 2016. Effect of the environment on the secondary metabolic profile of Tithonia diversifolia: a model for environmental metabolomics of plants. Scientific Reports, 6: 29265.

Shekhar, T.C. \& Anju, G. 2014. Antioxidant activity by DPPH radical scavenging method of Ageratum conyzoides Linn. leaves. American Journal of Ethnomedicine, 1(4): 244-249.

Shobana, F. \& Vinusha, C. 2017. Phytochemical screening and antimicrobial studies in leaf extract of Euphorbia milii. International Journal for Multidisciplinary Research, 1(1): 13-19.

Venkatachalam, D., Thavamani, S. \& Vijayan, S. 2018. Screening of Euphorbia hirta extracts for antioxidant activity. Indian Journal of Medical Research, 5(6).

Yelin, A. \& Kuntadi. 2019. Phytochemical identification of honey from several regions in Java and Sumbawa. International Conference on Biology and Applied Science (ICOBAS), 2120(1): 080024-1-080024-5. 
